ELÍAS Mariana Alfonsina y Ariel MENCIA, Textiles del Chaco. Catálogo del MEAB

Museo Etnográfico « Dr. Andrés Barbero », Asunción, 2012

\title{
Rodrigo Montani
}

\section{OpenEdition}

\section{Journals}

Edición electrónica

URL: https://journals.openedition.org/jsa/12708

DOI: 10.4000/jsa. 12708

ISSN: $1957-7842$

\section{Editor}

Société des américanistes

\section{Edición impresa}

Fecha de publicación: 15 septiembre 2013

Paginación: 236-243

ISSN: 0037-9174

\section{Referencia electrónica}

Rodrigo Montani, «ELIÁA Mariana Alfonsina y Ariel MENCIA, Textiles del Chaco. Catálogo del MEAB»,

Journal de la Société des américanistes [En línea], 99-1 | 2013, Publicado el 16 octubre 2013, consultado el 03 septiembre 2022. URL: http://journals.openedition.org/jsa/12708 ; DOl: https://doi.org/10.4000/ jsa. 12708

Este documento fue generado automáticamente el 3 septiembre 2022.

All rights reserved 


\section{ELÍAS Mariana Alfonsina y Ariel MENCIA, Textiles del Chaco. Catálogo del $M E A B$}

Museo Etnográfico « Dr. Andrés Barbero », Asunción, 2012

Rodrigo Montani

\section{REFERENCIA}

ELÍAS Mariana Alfonsina y Ariel MENCIA, Textiles del Chaco. Catálogo del MEAB, Museo

Etnográfico « Dr. Andrés Barbero », Asunción, 2012, 252 p.

1 Aunque a primera vista los textiles del Gran Chaco no presentan la calidad técnica, la variedad formal ni el simbolismo pasmoso de los andinos, son, sin embargo, la parcela de la cultura material de los indígenas chaqueños más diversa, compleja y significativa. Bolsos enlazados y tejidos, mantas y ponchos, fajas, vinchas y tocados, entre otros artefactos de su clase, dan cuenta de la ecología y de la historia de cada pueblo y despliegan además un código elocuente en el cual los chaqueños cifran categorías y relaciones cosmológicas y rituales, interétnicas, estatutarias, de género o de edad. El precioso catálogo de su importantísima colección, que el Museo Etnográfico Dr. Andrés Barbero (MEAB) de la ciudad de Asunción del Paraguay acaba de publicar, documenta precisamente la variedad y finura de las formas textiles chaqueñas y repasa lo que se sabe sobre sus funciones y significados.

Suscripto por la argentina Mariana Alfonsina Elías y por el paraguayo Ariel Mencia, el libro (de 22 por $33 \mathrm{~cm}$, en papel ilustración, con dibujos y fotos a todo color) está dividido en dos grandes secciones: por un lado, una larga introducción sobre la materia; por el otro, el catálogo propiamente dicho de los artefactos textiles del MEAB.

El estudio introductorio, a su vez, está dividido en tres textos. El primero, escrito por ambos autores, es una breve presentación de la investigación que originó el volumen (el análisis morfológico de las 373 piezas que forman el acervo textil del MEAB y el estudio 
de las fuentes bibliográficas y fotográficas asociadas), de los artefactos que contiene el catálogo y del criterio clasificatorio seguido. Luego figura un brevísimo texto general sobre los textiles chaqueños firmado por Mencia, cuyo valor reside en precisar el origen de los objetos textiles de la colección del MEAB (los viajes etnográficos de Max Schmidt y de Branislava Susnik, además de algunas donaciones de particulares), en puntualizar parte de la bibliografía publicada por Schmidt y Susnik que refiere a dichos objetos y en señalar algo que personalmente desconocía: una mención - quizá la más temprana - de las telas enlazadas chaqueñas en los escritos de Alvar Núñez Cabeza de Vaca. El último texto de la introducción se titula "Textiles indígenas del Gran Chaco Sudamericano » y es un extenso análisis comparativo de las formas, las funciones y los significados de los textiles en las distintas sociedades indígenas de la región, que Elías redactó después de estudiar las colecciones del MEAB y del Museo Etnográfico Juan B. Ambrosetti de la Universidad de Buenos Aires, y de revisar el grueso de la bibliografía publicada sobre el tema. (Hay un detalle formal poco feliz tanto en el escrito de Mencia como en el de Elías: en sendas bibliografías se duplican las referencias que ya figuran en las notas; por otro lado, dada la abundancia de citas hubiese convenido reemplazar las notas - difíciles de seguir - por el sistema de autor año.) Ilustran el texto de Elías 14 fotos y 27 dibujos, reproducidos u originales, además de un glosario textil, también con imágenes.

4 Las 51 páginas de Elías son las que merecen mayor comentario. Acertadamente, la autora abre su texto recordándonos que Textiles del Chaco... da cuenta de una colección museológica formada durante la primera mitad del siglo xx con artefactos recolectados en la frontera entre los territorios indígenas y los vectores de colonización (ingenios azucareros, misiones, fortines, estancias ganaderas y - sumo - explotaciones madereras), y nos evita caer en una visión estática tanto de las sociedades indígenas como de su cultura material. Agregaría que sin duda la colección refleja también los sesgos personales y de época de Schmidt, de Susnik y de las otras personas que donaron artefactos (quizá, por ejemplo, un interés por lo tradicional en detrimento de lo considerado aculturado, o por lo ritual o festivo en desmedro de los objetos de uso diario), así como las circunstancias fortuitas que permitieron recolectar determinadas piezas y no otras (por ejemplo, lo disponible, lo que los indígenas quisieron trocar, lo que era posible transportar, etc.). Tener presentes estas precondiciones nos evita creer que los materiales de museo puedan reflejar exhaustivamente los textiles producidos o usados por cada sociedad chaqueña - algo que el texto, en ocasiones, parece olvidar. La colección, y por ende también el catálogo, pasan necesariamente por alto ciertas técnicas, formas, colores, etc. conocidas y usadas por determinados grupos. Por ejemplo, como bien lo señala Elías, « [e]n las colecciones wichí, ayoreo e ishir [...] no se registran » (p. 47) bolsas semiesféricas con dos estructuras textiles; sin embargo, conozco de primera mano que entre los wichís estas bolsas sí existen.

5 "Textiles indígenas del Gran Chaco Sudamericano " aborda primero una serie de aspectos tecno-morfológicos generales (las materias primas y las formas de confección del hilo, las tinturas y las técnicas de teñido, las estructuras textiles y las formas de los artefactos) para luego describir las distintas categorías de textiles, repasar sus características pueblo por pueblo y detenerse en ciertas dimensiones formales que lo ameritan (especialmente en los diseños y los colores de los bolsos enlazados, de los bolsos de lana y de las mantas, ponchos y fajas). Pueden realizarse algunas objeciones menores a la descripción de los aspectos tecno-morfológicos. Por ejemplo, la autora señala que en el Chaco se utilizan tinturas de origen vegetal, animal y mineral, además de 
la anilina industrial incorporada durante el siglo xx (p. 33). La afirmación es sospechosa. La extensa mayoría de tinturas chaqueñas son de origen vegetal. Los wichís, por ejemplo, conocen sólo una tintura animal (la misma que consigna la autora): la cochinilla, que se utilizaba para la lana. Ignoro el uso de tinturas minerales, y el texto no aporta ninguna referencia al respecto. Cenizas y barros, si es que pueden contarse como minerales, no son tinturas, sino mordientes. Otra pequeña objeción es que el repertorio de puntos de enlazado es bastante incompleto; tan sólo entre los wichís, por ejemplo, existen varios otros que Elias no consigna: enlazados simple con una torsión (la variación loop-and-twist del simple looping de Emery 1980), el enlazado largo (una variación del figure-8 looping de Emery 1980) y el enlazado en ocho doble (la variación overlapping and interlaced del figure-8 looping de Emery 1980). Asimismo, en lo que concierne a la exposición de los aspectos técnicos y formales - y no sólo de ellos - hubiese sido más útil que los gráficos estuviesen intercalados en la parte correspondiente del texto, y que las referencias a las piezas del catálogo siguiesen la numeración arbitraria con la que realmente figuran de forma sucesiva en el catálogo (y no un número de catálogo que encabeza la ficha, pero cuya razón de ser permanece para el lector completamente oscura). Se puede corroborar, además, que en el glosario aparece un error descriptivo importante: los gráficos de los "sentidos de torcido de las fibras textiles» (p. 98) están mal construidos, pues S y Z señalan precisamente la inclinación que puede observarse en las hebras del hilo colocado en posición vertical: \y/, respectivamente.

Después de la descripción tecno-morfológica general, Elías repasa las categorías textiles que ordenan las 190 fichas del catálogo propiamente dicho: 1) bolsas cuadrangulares enlazadas con las fibras de las especies de bromelias textiles conocidas como caraguatá o cháguar, 2) bolsas hemisféricas - prefiero llamarlas semiesféricas - de caraguatá, 3) bolsas con base redondeada de caraguatá, 4) bolsas cuadrangulares de lana, 5) alforjas, 6) faldas, 7) typói, 8) mantas, 9) ponchos, 10) fajas, 11) cinturones, 12) coronas, 13) bandas frontales, 14) cintas para la cabeza, 15) cintillos y 16) collares, pendientes y brazaletes. Al leer la presentación de cada una de estas categorías uno queda convencido de que la autora ha observado atentamente muchísimas piezas y ha consultado con esmero una amplísima bibliografía sobre la cultura material de los chaqueños (lamentable y justificadamente, la autora no tuvo acceso a cuatro trabajos sobre los bolsos enlazados wichís que hubiesen enriquecido su análisis: Alvarsson 1992, 1994; Montani 2004, 2012). Fruto de la observación y de la lectura esmeradas, el texto de Elías presenta, pues, una contextualización sociocultural admirable de los textiles chaqueños y sugiere varias generalizaciones que a continuación comento dándoles una forma más arriesgada y definida.

7 Existe en el Chaco una asociación bastante sistemática entre las formas de los bolsos enlazados y las categorías de usuarios: los bolsos cuadrangulares medianos y grandes, enlazados generalmente en ocho con caraguatá, eran o son usados por los hombres para transportar las herramientas y los productos de sus actividades típicas (la caza y la pesca); las bolsas pequeñas, fabricadas principalmente con enlazado simple, en cordón o anudadas, en caraguatá, o bien más tardíamente tricotadas o tejidas en lana, eran usadas por los hombres para guardar y acarrear sus bienes personales (implementos para el fuego, amuletos de caza, adornos); los bolsos cuadrangulares grandes y las bolsas semiesféricas, ambas también enlazadas en caraguatá, eran o son artefactos femeninos destinados fundamentalmente a la recolección y al almacenamiento de bienes del grupo doméstico; por último, las bolsas enlazadas medianas muchas veces también se destinan al mercado de artesanías étnicas (pp.40-42, 55-56). Elías argumenta, retomando 
esencialmente a Susnik, que las bolsas semiesféricas están estrechamente vinculadas con las mujeres porque eran o son usadas fundamentalmente en actividades femeninas (recolección y almacenamiento de los alimentos del grupo doméstico), y porque enlazarlas fue o sigue siendo la tarea femenina arquetípica, una actividad con « múltiples reminiscencias mitológicas » (p. 45). En efecto, al menos entre los wichís, tanto desde el punto de vista sociológico, formal, funcional como simbólico, las bolsas semiesféricas pueden ser pensadas como artefactos construidos por las mujeres sobre la metáfora del útero: como he propuesto en otro lado (Montani 2008, 2012), estas bolsas cargueras son una suerte de "útero externo » y son, por lo tanto, un artefacto definitorio de la feminidad.

8 Del análisis de los diseños de los bolsos enlazados, tricotados y tejidos con trama y urdimbre se puede deducir también algunas constataciones generales. La primera concierne a las mismas fuentes documentales del trabajo regional comparativo. Por desgracia, a pesar de que los bolsos con diseños son típicos de las sociedades chaqueñas, hasta el momento sólo contamos con estudios sistemáticos sobre los diseños enlazados wichís (Alvarsson 1994; Koschitzky 1992; Millán 1944; Montani 2004, 2007, 2012). La investigación de los diseños es una tarea ardua, porque luego de comprender las posibilidad y constreñimientos técnicos debemos estudiar las formas de los diseños (he propuesto que, al menos en el caso wichí, resulta útil separar el motivo del patrón de simetría que guía su distribución en el plano) y, simultáneamente, la relación compleja de estas formas con los nombres de diseño. Tampoco contamos con estudios exhaustivos de los diseños tricotados y tejidos para ninguna sociedad chaqueña. Como consecuencia, el análisis comparativo de la autora difícilmente pueda sobrepasar el aspecto formal. Otra constatación importante es aquella que concierne a la varianza y la recurrencia de los diseños chaqueños, y a la posibilidad de establecer estilos étnicos, regionales (de sectores del Chaco) o areales (del Chaco en su conjunto). Como correctamente señala Elías, tanto en los diseños enlazados como en los tricotados y tejidos, y tanto en los bolsos como en las mantas, ponchos, fajas y vinchas, existen diseños nombrados que son comunes a varios pueblos (e incluso, agrego en lo personal, a pueblos fuera del Chaco, como el zigzag horizontal con nombre de pieles de serpientes); y, contrariamente, existen otros que son exclusivos de un grupo étnico o intraétnico, o de un conjunto « microregional ». El estudio de las colecciones de museo puede servir para abordar el aspecto formal del asunto, pero la comprensión cabal del problema demanda, de modo urgente, más y mejor etnografía.

Otra sugerencia generalizadora del texto de Elías es la importancia que tiene en el diseño de lo que denominó « la tríada cromática chaqueña »: blanco, rojo, negro. Sociedad tras sociedad vemos que los dibujos textiles están las más de las veces construidos con estos « colores» (o con dos de ellos), a veces de manera solapada, reemplazando, por ejemplo, el blanco por el crema o el negro por el azul o el rojo por el rosa. (Recordemos que en wichí al azul se le dice -chalaj, el verbo neutro que denomina al «negro ».) Es indudable que para comprender el cromatismo textil y el valor de dicho cromatismo se impone un estudio previo de la clasificación cromática indígena.

Dije que el trabajo de Elías es una síntesis regional sobre los textiles chaqueños. Como tal, además de brindarle al etnógrafo especializado en un grupo una visión regional de conjunto, le permite encontrar o rencontrar detalles comparativos interesantes. Leyendo «Textiles indígenas...» recordé que Fernández Distel (1983) hablaba de la bolsa 
semiesférica ubekaháni, que le sirve a la madre ayoreo para transportar durante las marchas a sus hijos pequeños y los bienes domésticos.

11 A su vez, el detalle me trajo a la memoria que existe por lo menos una mención histórica de bolsos semiesféricos usados por los wichís como recipiente para cargar el bebé (Baldrich 1890, pp. 236-237), y que en una escena poco conocida de su mitología la hija de Sol carga en su sichet (la bolsa semiesférica) al trickster Tukwaj. Un nuevo detalle comparativo que se suma a una lista amplia y llamativa de semejanzas entre la cultura material ayoreo y la wichí (Montani 2012).

Elías no es antropóloga, sino licenciada en Artes, y algunas inexactitudes de su escrito se justifican quizá por dicha filiación profesional. En ocasiones, por ejemplo, rigidiza las clasificaciones indígenas de los textiles. Repite, pues, algo inverosímil, que los tobas del oeste de Formosa, estudiados por Arenas (2003), clasifican las bolsas cuadrangulares según el punto de enlazado (p. 40). Lo inverosímil no es que lo hagan, sino que pensemos que dicha tipología constituye algo realmente sistemático y excluyente de otras posibles. El error se vincula también con el uso siempre complejo de las expresiones indígenas - en este caso, de las referidas a los artefactos textiles - por fuera de una compresión global de la lengua; esta falta de perspectiva distorsiona la traducción y termina por presentar como palabras inanalizables lo que en realidad son nombres simples, derivados, compuestos, verbos, frases, etc. (al estilo del hile wichí, «bolsa cuadrangular enlazada ", y sus formas vinculadas: hile-lhos, « bolsa cuadrangular enlazada chica », hile-lhos ta hu'aqtsaj-ch'utey, " bolsa cuadrangular enlazada chica con el diseño orejas de la mulita ", etc.) o bien por presentar como nombre de un artefacto un término que en realidad refiere a algo más general (como puede suceder con otra de las denominaciones del bolso semiesférico wichí, ulhekw, que literalmente quiere decir « mi carga »). Requiere también rectificación la repetición que Elías hace de la opinión de Koschitzky (1992, p. 40) según la cual sichet, el nombre wichí para el bolso semiesférico, es una palabra de origen quichua usada sólo en la Argentina. Esto es algo que la propia Koschitzky no prueba y que hasta donde sé los diccionarios quechuas y quichuas desdicen. Por último, no puede pasar inadvertido el problema del significado de las categorías que ordenan los artefactos textiles en el trabajo de Elías y en el catálogo mismo: ¿reflejan el punto de vista nativo?, ¿en qué sentido?, ¿siguen clasificaciones lingüísticas, funcionales, etc. de los indígenas o son simples etiquetas museográficas construidas a partir del análisis morfológico combinado con nuestras categorías intuitivas de artefactos (i. e., las que nuestras lenguas distinguen, las que normalmente fabricamos y usamos, etc.)? Hay por lo menos una distinción que creo demasiado externa: aquella que separa las «bandas frontales» de las "cintas para la cabeza " (pp. 226-236); los wichís, por ponerlos nuevamente como ejemplo, agrupan unas y otras bajo el único rótulo de « su vincha » (lap’aqiche).

13 Los problemas de estilo en el texto de Elías no son achacables a su formación y por desgracia no son pocos: un abuso de la barra para separar sinónimos, como si se tratase de la conjunción disyuntiva « o » (algo de por sí incorrecto), un exceso de sinónimos que entorpecen la lectura, una puntuación defectuosa que se repite (una coma separando el sujeto del predicado), etc. Pero más allá de estos aspectos algo desconcertantes, Textiles del Chaco... no deja de ser una obra preciosa e importantísima, porque nada puede opacar el valor estético y documental de las 16 fotos originales a página completa y de las 190 exhaustivas fichas de artefactos - realizadas a partir de las de Susnik - con sus respectivas fotografías - también originales - que conforman el catálogo propiamente 
dicho. En él, bolsos, faldas, vestidos, manta, ponchos, fajas, cintos, tocados, vinchas, collares, pendientes y brazaletes exhiben sus formas, texturas y colores para dar cuenta de la destreza técnica, de la inventiva y de las preocupaciones pragmáticas, éticas y estéticas de los pueblos del Gran Chaco.

\section{BIBLIOGRAFÍA}

\section{ALVARSSON Jan-Åke}

1992 « Artifacts in ethnographic description: some ideas based on an analysis of three stringbags from the Mataco Indians of Bolivia ", Antropoloska Studier, 49, pp. 2-25.

1994 Through the web of the string-bag: weenhayek culture and symbolism as reflected in caraguatá artefacts [Ethnologiska Studier, 42, precirculated edition], Göteborg Etnografiska Museum, Göteborg.

\section{ARENAS Pastor}

2003 Etnografía y alimentación entre los toba-ñachilamoleek y wichí-lhuku'tas del Chaco central (Argentina), edición del autor, Buenos Aires.

\section{BALDRICH Amadeo}

1890 Las comarcas vírgenes: el Chaco central norte, Peuser, Buenos Aires.

\section{EMERY Irene}

1980 The primary structure of fabrics: an illustrated classification, The Textile Museum, Washington.

\section{FERNÁNDEZ DISTEL Alicia}

1983 « La cultura material de los ayoreo del Chaco boreal », Scripta Ethnologica (supplementa 3), pp. 4-78.

\section{KOSCHITZKY Monica von}

1992 Las telas de malla de los wichí-Mataco: su elaboración, su función y una posible interpretación de los motivos, Centro Argentino de Etnología Americana, Buenos Aires.

\section{MILLÁN María Delia}

1944 « Forma y significado de los motivos ornamentales de las "llicas" chaquenses ", Relaciones de la Sociedad Argentina de Antropología, 4, pp. 69-76.

\section{MONTANI Rodrigo}

2004 Categorías materiales y formas sociales entre los wichís de Los Baldes (Salta, Argentina), tesis de licenciatura en Antropología, Universidad Nacional de Rosario.

2007 « Formas y significados de los diseños de los bolsos enlazados por los wichí del Gran Chaco ", Separata, 5 (12), pp. 35-67.

2008 « Metáforas sólidas del género: mujeres y tejido entre los wichí », in Silvia Hirsch (ed.), Mujeres indígenas en la Argentina: cuerpo, trabajo y poder, Biblos, Buenos Aires, pp. 153-177.

2012 El mundo de las cosas entre los wichís del Gran Chaco: un ensayo etnolingüístico, tesis de doctorado en Letras, Universidad Nacional de Córdoba. 


\section{AUTORES}

\section{RODRIGO MONTANI}

Becario posdoctoral del CONICET, Argentina 